\title{
A revolta digital: impacto das redes sociais da internet nos protestos de rua dos países árabes em 2011
} \author{
countries in 2011 \\ Rogério Martins de Souza ${ }^{1}$ \\ Débora Alves da Costa ${ }^{2}$
}

Digital riot: The influence of social medias in the streets rebellions of arab

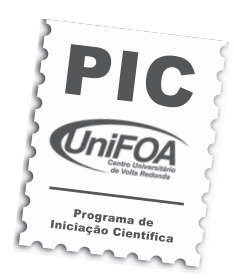

Palavras-chave
Oriente Médio
Mobilização
Informação
Poder

Internet

\section{Resumo}

No mundo de hoje, a internet pode ser vista como um meio de comunicação no qual as pessoas se informam sobre os acontecimentos do mundo e interagem com outros indivíduos. Nos últimos anos, a importância das redes sociais da grande rede vem crescendo e ganhando mais visibilidade como elemento de mobilização popular. Em 2011- em revoltas nos países do norte da África, que ficaram conhecidas como Primavera Árabe- jovens usaram essa tecnologia e conseguiram levar multidões a protestarem nas ruas. Este artigo se propõe a analisar o papel das mídias digitais nas revoltas que levaram à queda de regimes opressores naquela região.

\section{Abstract}

Nowadays, internet can be seen like a medium that people get to know about what's happening and interact with other people. In the last years, the importance of internet social medias is growing and getting more views working in the intention of popular mobilization. In 2011, while the street riots were happening in north of Africa, called as Arab Spring, young people used this technology to connect and claimed the crowd to protest in the streets. This article intents to study the role of digital medias in the riots that led to the fall of the totalitarian regimes on that region.
Key words

Middle East

Mobilization

Information

Power

Internet

\footnotetext{
${ }^{1}$ Doutor em Comunicação pela UFRJ. Professor dos cursos de Jornalismo e Publicidade e Propaganda do Centro Universitário de Volta Redonda - UNIFOA

${ }^{2}$ Aluna do $3^{\circ}$ período do Curso de Publicidade e Propaganda em Comunicação do UNIFOA - Centro Universitário de Volta Redonda.
}

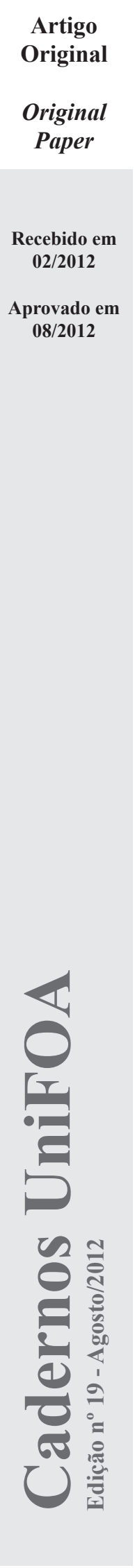


Situado em uma área estratégica, entre o norte da África e a Europa, o Oriente Médio é, há décadas, marcado por conflitos entre seus povos. Todos os dias, ao ligarmos a televisão, podemos encontrar no noticiário noturno ao menos uma reportagem referente a essa região. Porém, em janeiro de 2011, o mundo se deparou com revoltas populares que marcaram a história daquela região. A Primavera Árabe, como ficou conhecida, foi um momento histórico que aflorou no início de 2011, em busca da democracia nos países islâmicos, que conseguiu colocar um fim em governos ditatoriais de mais de vinte anos no poder. Um dos casos que pode ser citado é o Egito. Após dezoito dias de conflitos, o ditador Mubarak, no governo há quase trinta anos, renunciou à presidência, dando a vitória aos rebeldes egípcios.

O Egito não foi o primeiro país do norte da África a conseguir derrubar um governo ditatorial. A população de países como Tunísia e Líbia também tiveram sucesso em seus protestos, sendo que o ditador líbio, Muamar Kadafi, depois de 42 anos no poder, ainda resistiu por alguns meses até ser morto por rebeldes em outubro de 2011. O fator que nos leva a dar um pouco mais de atenção a esses conflitos não é apenas o sucesso que os protestos tiveram e sim os meios de comunicação que foram utilizados pela população para conseguir essa grande mobilização.

Com o surgimento da internet e suas redes sociais, hoje em dia é muito mais fácil para as pessoas terem acesso a qualquer tipo de informação, pois essa tecnologia nos permite falar de "todos para todos" (CASTELLS, 2003, p. 54). E foi através de redes sociais como Facebook e Twitter que multidões correram às praças das capitais de países árabes, conseguindo se mobilizar e mudar a história de seus países, abalando até mesmo a estrutura de outros.

Este artigo irá analisar como a informação, aliada à capacidade de mobilização das pessoas via internet, colaborou com o processo de deslegitimação do poder de antigos líderes há décadas no comando. Usou-se como suporte de análise diversos artigos escritos "no calor da hora", ou seja, durante ou logo após as manifestações de rua nos países do norte da África; além de livros científicos que versam sobre o poder das redes sociais na contemporaneidade.
Sem pretender esgotar o assunto, buscamos, dessa forma, contribuir com as pesquisas sobre o poder das mídias digitais na era contemporânea e entender as novas formas de mobilização que as sociedades têm utilizado para atuar politicamente.

\section{O Oriente Médio: uma região conturbada}

A expressão Oriente Médio é recente, antes, usava-se com mais frequência "Oriente Próximo". Sob um ponto de vista mais limitado, o Oriente Médio é uma região da Ásia formada pelos seguintes países: Irã, Iraque, Arábia Saudita, Turquia, Afeganistão, Iêmen, Kuwait, Omã, Emirados Árabes Unidos, Barein, Catar, Jordânia, Israel, Síria e Líbano. Porém, por apresentarem características semelhantes, outras regiões são incluídas quando falamos em Oriente Médio. O norte da África - países como Egito, Líbia, Tunísia, Argélia e Marrocos - apresenta desertos, fala a língua árabe e pratica a religião muçulmana, características da região. O Egito, em particular, participou sempre ativamente de tudo o que acontecia no Oriente Médio.

Um elemento é comum a quase todo o Oriente Médio: o petróleo. Essa área, especialmente a península arábica, está sobre imensas reservas deste combustível natural. Apesar de tantas outras fontes de energia (como a atômica e a solar) terem surgido, o petróleo ainda é considerada a mais importante e mais utilizada. Essa abundância petrolífera dá ao Oriente Médio grande destaque no mundo contemporâneo. Potências como a Rússia e os EUA são fortes produtoras do "ouro negro", mas sem o fornecimento do Oriente Médio, com certeza, o mundo industrial pararia ou andaria mais devagar (KARNAL, 1994, p.12).

O petróleo trouxe ao Oriente Médio uma realidade estranha. Alguns países, como Kuwait, transformaram-se em "ilhas da fantasia", onde a vida parece correr mais fácil do que no resto do mundo: muito dinheiro, ausência de impostos, serviços públicos abundantes e quase gratuitos. Em outras áreas, como Irã e Iraque, apesar das riquezas provenientes do petróleo, a maioria da população vive situa- 
ções difíceis, já que o dinheiro das exportações não é distribuído de forma equilibrada para a sociedade (Idem, 1994).

Ao mesmo tempo em que o petróleo sustenta a vida econômica de grande parte do Oriente Médio, ele também patrocina a corrida armamentista e os interesses estrangeiros na região. Esses dois elementos colaboram para torná-lo instável. A região do Golfo Pérsicoonde se situa o Iraque, por exemplo- foi duas vezes invadida pelo exército dos Estados Unidos (em 1991 e em 2003), quando o exército americano declarou como uma "guerra pela liberdade" um conflito no qual motivos bem mais complexos estavam em jogo, entre eles o petróleo abundante da região.

O Oriente Médio não é apenas importante apenas pelo açúcar, café ou a gasolina que movimenta as cidades. Ele também é importante porque deu ao mundo três grandes religiões: o judaísmo, o cristianismo e o islamismo.

A civilização e a história começaram em boa parte na região do Oriente Médio e no norte da África. As cidades ao sul da Mesopotâmia, onde hoje estão o Iraque e o Kuwait, foram berço da mais antiga civilização escrita. Às margens do Nilo, floresceu o Egito, cujas realizações ainda encantam as pessoas. No atual Irã, surgiram os persas, criadores de um vasto e bem organizado império. Da região hoje ocupada pelo Líbano surgiu o alfabeto.

Na ciência, o progresso mulçumano foi admirável. Nomes de estrelas como Aldebarã são o testemunho do progresso da astronomia árabe. Além de grandes inventores, os povos da região mulçumana foram notáveis também pela difusão de conhecimentos de outras civilizações como o papel, a pólvora, a bússola e o astrolábio.

Todos os povos conheceram guerras. Para os judeus, a guerra é simbolizada por Armagedon, um lugar mítico, que consta na Bíblia como uma região de desastre, de tragédia. Israel nasceu e cresceu sob o signo de Armagedon, ora no ataque, ora na defesa (Ibid). Há décadas, judeus e palestinos vivem em conflito, disputando a mesma região da Cisjordânia, com vantagem para Israel, cujo governo é apoiado pelos Estados Unidos.

Após a Segunda Guerra Mundial, a recém-criada Organização das Nações Unidas (ONU), começava a preparar a votação de um estado judeu, ao mesmo tempo em que a Inglaterra, enfraquecida pela guerra, anunciava seu desejo de abandonar a Palestina. A situação interna da Palestina era grave: tanto os árabes como os judeus estavam entrando em crescentes conflitos. Os judeus organizaram grupos militares como o Irgun, com o objetivo de enfrentar os árabes e os britânicos na Palestina.

Em 1947, a ONU fazia uma partilha do território da Palestina, dividindo-o entre árabes e judeus e tornando Jerusalém uma cidade internacional. Em maio de 1948, tomando a frente dos acontecimentos, David Bem Gurión proclamava o Estado de Israel no Museu TelAviv. Os países árabes vizinhos organizaram imediatamente uma guerra. Começava a primeira guerra oficial entre árabes e israelenses.

Jerusalém foi um palco privilegiado das contradições dessa guerra. Os dois lados praticavam uma luta quase corpo a corpo nas ruas estreitas da cidade. O bairro judeu foi tomado pela Liga Árabe e várias sinagogas foram incendiadas. Os soldados israelenses disparavam contra as lojas árabes, matando civis. Após muitos combates, a colina de Kastel foi dominada pelos israelenses, favorecendo o domínio da cidade de Jerusalém.

Após varias tréguas e retomadas de combate, a vitória israelense estava assegurada. Em 1949, os países árabes pediam a paz. Israel crescera muito além do que a ONU tinha estipulado, ocupando, inclusive, metade de Jerusalém. A existência de atritos internos entre os árabes e judeus é um argumento para que alguns autores afirmem ser política, e não religiosa, a causa dos choques no Oriente Médio. A tradição do Oriente é juntar todas as formas de ver o mundo, inclusive as políticas e religiosas.

Certamente a religião sozinha não explica nada no Oriente Médio, bem como a política. É preciso estar atento à variedade de fatores que levam às guerras, fatores que vão do subsolo (petróleo) ao céu (religião) (Idem, 1994). No que concerne aos acontecimentos recentes da Primavera Árabe, o diferencial é que pela primeira vez uma nova mídia foi utilizada como mobilização das revoltas populares em países marcados por governos ditatoriais: as redes sociais da internet. 


\section{Internet e mobilização}

Antes de qualquer coisa, é importante saber do que realmente se trata a "Primavera Árabe". Esse termo se refere a uma onda de manifestações ocorridas em países árabes do norte da África, desde o final de 2010, que tiveram inicio na Tunísia, após o suicídio de um vendedor ambulante na cidade de Sidi Bouzid. Por não conseguir sua licença para trabalhar nas ruas, o homem passou anos sendo assediado pelas autoridades tunisianas e, por não possuir o dinheiro para pagar aos fiscais, teve sua mercadoria confiscada. Desesperado, o comerciante acabou por atear fogo em si próprio, desencadeando uma onda de protestos. Os protestos prosseguiram ao longo do começo de 2011 e seus estímulos vinham do excessivo aumento dos preços dos alimentos básicos, que acabou por aumentar a insatisfação popular diante das más condições de vida da maior parte da população tunisiana e da corrupção do governo. A insatisfação aumentou com as revelações dos telefonemas do Departamento de Estado americano vazados pelo Wikileaks, que expunham as tramas corruptas do presidente Ben Ali (BEAS, 2011).

Os bloggers evitaram os censores tunisinos e evitaram os media controlados pelo estado para protestarem sobre a ausência de democracia na Tunísia. Pela internet, conseguiram tal feito, não apenas dentro do país como para do mundo. O governo autoritário de Ben Ali tinha pouca tolerância com a liberdade na Internet, tendo encerrado muitos sites e detido vários bloggers. Mas, jovens tunisinos- como Dalhoumi, que se encontrava num ciber-café em Tunis- encontraram formas de enviar as mensagens. As autoridades, inicialmente, tentaram bloquear os vídeos, gravados em celulares, mostrando as mortes de manifestantes, em dezembro, o que deu inicio a uma revolta nacional (CANALMOZ, 2011).

Os acontecimentos na Tunísia se espalharam pelos países vizinhos, provocando uma onda revolucionária em grande parte do Oriente Médio. A diferença era que agora, nas revoltas populares, as manifestações organizadas provinham primeiramente da internet, para depois chegar às ruas (PEREIRA, 2011).

$\mathrm{Na}$ Líbia, a mobilização começou com uma onda de protestos populares com reivin- dicações sociais e políticas. Assim como na Tunísia, os manifestantes exigiam liberdade, democracia e mais respeito pelos direitos humanos. Alguns intelectuais aliaram-se aos manifestantes, porém, a maioria foi presa, como o comentarista político Jamal al-Hajji, acusado de ter apelado em forma de protesto, usando a internet, em favor de maior liberdade na Líbia.

Não demorou muito para que a parte ocidental da Líbia também começasse a cair sob o controle dos grupos anti-Kadafi, deixando Tripoli, a capital do país, cercada por cidades controladas pelos manifestantes. A maioria das nações condenou o governo da Líbia de Kadafi pelo uso de violência contra os manifestantes, que já matou centenas de pessoas no país.

Todos esses acontecimentos atraíram a atenção de todo o mundo para aquela região, despertando a curiosidade de muitos estudiosos para o modo como esses protestos foram organizados. A curiosidade era sobre o papel das redes sociais da internet, como Facebook e Twitter, nas mobilizações de rua nos países árabes. Com o amplo acesso à informação que é permitida pela internet, fica cada vez mais difícil a permanência no poder de regimes que sejam totalitários. Se antes das mídias digitais, o controle da população em grande parte se dava pelo uso da força de um estado repressor e mantendo a televisão, jornais e rádios sob vigilância constante, com o fluxo em tempo real das informações disseminadas pela internet, esse controle começou a ruir, como salienta Cabral:

Por todo o exposto, entende-se que a Primavera Árabe trata-se, na verdade, de um movimento democrático provavelmente associado à globalização da informação e aos novos meios de comunicação, em especial a internet. Assim sendo, o amplo acesso à informação no mundo atual tem tornado cada vez mais difícil a permanência de regimes totalitários, tendo em vista que a internet retira dos regimes não democráticos a capacidade de controlar a informação. Além disso, entende-se que o movimento conhecido como Primavera Árabe representa um anseio popular legítimo, em que se busca alcançar um direito (right to democracy) reconhecido pela Resolução no 1999/57 das Nações Unidas (CABRAL, 2011). 
As mídias tradicionais são conhecidas pela chamada comunicação de massas, na qual a característica básica é a comunicação unilateral, ou seja, de poucos para muitos, como na televisão. A internet, por outro lado, nos permite falar de todos para todos, sobre qualquer assunto, em qualquer lugar. Permite dar voz àqueles que não possuem e propicia aos cidadãos o direito de expressar sua opinião. Segundo Jenkins, essas mídias - a tradicional e a digital - estão hoje em processo de colisão, ocasionando uma nova cultura da convergência (JENKINS, 2009, p. 25). Os recentes acontecimentos no norte da África nos fazem perceber que essa tecnologia tem sim a capacidade de ajudar um povo a mudar a história de seu país. É claro que a internet, por si só, não deflagra revoluções - no caso da Primavera Árabe, como assinala Viana (2011), ela na verdade potencializou um anseio por mudanças em sociedades insatisfeitas com os rumos da política e da situação socioeconômica.

Por fim, verifica-se que a Primavera Árabe demonstra que a informação aliada à capacidade de mobilização das pessoas via internet representam ferramentas interessantes para a destruição de regimes ditatoriais. Ademais, é importante observar que a preservação dos canais de informação será fundamental para a construção de Estados democráticos de direito, em substituição às monarquias absolutistas e às repúblicas ditatoriais do norte da África e do Oriente Médio (CABRAL, 2011)

\section{As revoltas populares no Egito}

No início de 2011, mais exatamente em janeiro, os noticiários estiveram focados em um país específico do norte da África: o Egito. Após a queda do presidente na Tunisia, a população egípcia se mobilizou para protestar contra o governo do atual ex-presidente Hosni Mubarak.

Tudo começou com um vídeo de um jovem sendo torturado pela polícia egípcia, vídeo este que vazou para a internet. Para tentar abafar o caso, Mubarak tentou inutilmente organizar uma festa popular na data em que se comemorava o Dia da Polícia Egípcia. Indignados, jovens do Cairo resolveram usar a ocasião para protestar, e assim, através da internet, combinaram de se reunir na Praça Tharir. Não foi dito a hora, nem mesmo um local específico para se encontrarem, porém, havia a certeza de que todos acabariam se encontrando. A mobilização, iniciada em redes sociais da internet, inspirou pesquisadores a considerar as manifestações como próprias da blogosfera:

\begin{abstract}
A lógica da revolução foi a lógica da blogosfera. Isto não acontece por decisão de alguém. A cultura política, a cultura das construções de relação, está se alterando. Se você vê televisão o dia inteiro, você acaba se tornando um cara mais passivo, você aceita ser liderado. Quando você passa a atuar na internet, você começa a perceber que há outra relação: fala, interfere, discute, critica, debate, segue as pessoas que quer, não segue as pessoas que não quer. E fala na relação de muitos para muitos. Eu tenho certeza de que este tipo de ativismo influenciou na hora em que eles foram para a rua. Quem foi primeiro (à Praça Tahrir) foram estes jovens (que usam a internet para protestar). Eles construíram o primeiro dia da manifestação, e foram a partir da lógica que eles estavam acostumados a vivenciar na sua atividade militante (ROVAI, apud PRESTES, 2011).
\end{abstract}

Os protestos tiveram início no dia 25 de janeiro de 2011, em várias cidades como Cairo, Alexandria, Suez e Ismaília. Mais de 15 mil pessoas foram às ruas demonstrar sua indignação. Nos dias que se seguiram, os protestos continuaram. Com aumento da violência, tanto por parte dos manifestantes quanto da polícia, prédios foram incendiados e as primeiras mortes começaram a ocorrer. Em Suez, os manifestantes tomaram a base policial, libertando todos aqueles que foram detidos nos dias anteriores. No final da tarde de 28 de janeiro, o prédio do Partido Nacional Democrata, no Cairo foi incendiado.

Os protestos continuaram com os manifestantes clamando pela renúncia de Mubarak. Para tentar conter a multidão, o governo tentou implantar o toque de recolher às $18 \mathrm{~h}$, no que foi 
desobedecido pelos manifestantes, que se organizavam em grupos familiares para se proteger.

Em 31 de Janeiro, os manifestantes convocaram uma greve geral e para tentar controlar a crise, Mubarak anunciou uma troca de ministros. Porém, os manifestos continuaram, agora sem violência.

Mubarak tentou sustentar-se em sua posição, negando-se à renúncia até as eleições em setembro, nas quais ele afirmou que não iria concorrer. Com isso, as manifestações se seguiram durante toda a madrugada dos dias 2 e 3 de fevereiro.

Com a Praça de Tharir, no Cairo, tomada por manifestantes, em 10 de fevereiro o presidente fez um pronunciamento, passando o governo do país para o vice-presidente Omar Suleiman. A população reagiu com fúria, exigindo que Mubarak renunciasse à presidência do Egito.

Foi então, em 11 de fevereiro, após 18 dias de protestos, que Mubarak anunciou sua renúncia ao cargo de presidente do Egito. Os revoltosos comemoraram: tinham afinal destituído um presidente estabelecido no poder há quatro décadas.

Ainda é cedo para dimensionar com certeza o papel das redes sociais da internet na queda do regime egípcio, mas uma certeza pode se ter: na Primavera Árabe, a internet, de alguma forma, ajudou as pessoas a se mobilizarem para protestar legitimamente contra governos dos quais discordavam - pelo computador, ou reunidos nas praças das capitais.

\footnotetext{
"Não dá para adivinhar o que vai acontecer daqui para frente, mas há dezenas de milhões de jovens no mundo árabe prestando muita atenção ao que acaba de ocorrer no Egito", diz Andy Carvin. Estrategista-sênior para mídias sociais na NPR, a respeitada rede pública de rádio americana, Carvin organiza comunidades on-line há mais de uma década. Durante a revolta, ativou contatos no Egito e tuitou 18 dias sem parar, atuando como editor-curador do noticiário. Viesse ele de jornalistas ou ativistas, Carvin impôs um padrão de qualidade (COELHO, 2011).
}

Não se pode esquecer que no Egito a internet também funcionou como aliada da mídia tradicional, cujo papel, na cobertura das revoltas populares, não pode ser debitado. Como lembra o escritor Jeffrey Ghannam (2011), houve de fato uma convergência entre as mídias tradicionais e a nova cultura digital:

\begin{abstract}
Também a mídia tradicional teve papel importante. Canais via satélite, árabes transmitiram a cobertura quase ininterrupta dos protestos, contando com as parabólicas onipresentes em toda a região. A convergência das mídias social e tradicional mostrou ser essencial para difundir mensagens. Em entrevista à Rádio França Internacional, Sami Bem Gharbia, cofundador do blog Nawaat, disse que essa foi a caixa de ressonância na luta da rua (GHANNAM, 2011).
\end{abstract}

\section{Considerações Finais}

A internet é uma tecnologia que, atualmente, tem grande influência nas sociedades em todo o mundo. Para grande parte dos cidadãos, tornou-se comum o acesso, pelo menos uma vez ao dia, de algum site de busca ou rede social para fazer uma pesquisa ou saber mais sobre um assunto muito comentado na televisão. Milhões de pessoas estão hoje conectadas aos assuntos do mundo, e o fenômeno não para de crescer.

Com o surgimento das redes sociais (Twitter, Facebook, Orkut etc) surgiu a chamada interconexão. Pessoas que estavam separadas geograficamente, agora estão conectadas a um grupo de indivíduos com interesses em comum. Essas comunidades virtuais acabaram proporcionando a discussão e a troca de experiência entre as pessoas, tornando essa interação cada vez mais ávida e maior (LEVY, 1999, p. 33).

Essa tecnologia mudou a maneira como as pessoas viam o mundo. $\mathrm{O}$ conhecimento se tornou mais palpável, a liberdade de expressão se tornou algo mais visível. Por meio de equipamentos cada vez mais baratos e acessíveis à população, vão surgindo vários exemplos de utilização de mídias digitais em protestos contra desmandos de governos e regimes. Por outro lado, governos totalitários do mundo de hoje sabem que a internet é um risco ao seu poder e tratam de tentar censurá-la, por inúmeras formas. 
Como ressalta Jenkins, este é um dos paradoxos da política de democratização no meio virtual: de um lado, mais fontes acessíveis de informação em busca da democratização da informação; de outro, governos que tentam controlar o acesso dos cidadãos à grande rede, tal como os países totalitários que, em várias partes do mundo ainda hoje proíbem o acesso a determinados sites e redes sociais (JENKINS, 2009).

A Primavera Árabe não trouxe apenas uma mudança radical em países onde a população vivia oprimida por governos ditatoriais, trouxe também uma nova visão de como a internet é e como a mesma pode ser usada em favor da população.

Durante os protestos no Egito, a internet não foi apenas usada como um meio de comunicação para informar ao mundo a situação em que o país se encontrava, mas também como um meio para que a população pudesse se unir. Mesmo com a tentativa do ex-presidente Mubarak de cortar o acesso à internet, os egípcios souberam usar as redes sociais para burlar a vigilância do poder. Um exemplo é o site de busca Google, que criou um sistema chamado "Speak to Tweet" para que eles pudessem usar o Twitter através de um sistema de voz.

Este é apenas um exemplo de como a internet $\mathrm{e}$ as redes sociais foram usadas na Primavera Árabe. Durante as manifestações de rua, era comum encontrar imagens de pessoas segurando cartazes que faziam alusão à internet, nos quais o nome de alguma rede social era seguido de incitação à revolta nas ruas.

A internet não foi a razão dos protestos terem se iniciado. Ela foi, sim, usada de maneira influente para que os protestos fossem organizados e as populações desses países árabes pudessem se expressar.

Isso nos mostra que a internet pode ser utilizada de outra maneira, além da troca de informações ou interações sociais. É preciso enxergar esse "poder" que a internet pode nos dar e usá-lo de maneira correta. Afinal, do mesmo jeito em que foi usada para derrubar governos ditatoriais, a internet também pode ser usada para fortalecê-los. 


\section{Referências:}

1. BEAS, Diego. A rua conectada com a rede. In: Jornal O Globo, 12 de fevereiro de 2011.

2. CABRAL, Bruno Fontenele; CANGUSSU, Débora Dadiani Dantas "Primavera árabe": reflexões sobre a existência do direito à democracia ("right to democracy"). Jus Navigandi, Teresina, ano 16, n. 2795, 25fev. 2011 . Disponível em: $<$ http://jus.com.br/revista/ texto/18576>. Acesso em: 11 abr. 2012.

3. COELHO, Luciana. O papel das redes sociais no Egito. Olhares Míopes, Fevereiro de 2011. Link ( HYPERLINK “ http://ww w. olharesmiopes. com/2011/02/o-papel-das-redessociais-no-egito.html" olharesmiopes.com/2011/02/o-papel-dasredes-sociais-no-egito.html_).

4. CANALMOZ. Internet "ajudou" a revolução na Tunísia. Janeiro de 2011. Link (_ HYPERLINK "http:// macua.blogs.com/moambique para todos/2011/01/internet-ajudou-arevolu $\%$ C 3\% A 7\% C 3\% A 3 o-natun $\% \mathrm{C} 3 \% \mathrm{ADsia} \cdot \mathrm{html} "$

5. CASTELLS, Manuel. A galáxia da internet: reflexões sobre a internet, negócios e a sociedade. São Paulo: Editora Zahar, Coleção Interface, 2003.
6. GHANNAM, Jeffrey. A revolução das redes sociais? In: O Globo, 21 de fevereiro de 2011.

7. JENKINS, Henry. Cultura da convergência. São Paulo: Editora Atlas, 2009.

8. KARNAL, Leandro. Oriente Médio. Ponto de Apoio. Editora Scipione, 1994.

9. LEVY, Pierre. Cibercultura. São Paulo, Editora 34, 1999.

10. PEREIRA, Merval. A força das redes. Jornal O Globo, 12 de abril de 2011

11. PRESTES, Felipe. A lógica da revolução no Egito foi a lógica da blogosfera. Entrevista com Rentato Rovai. Disponível no site Sul 21, no link http://sul21.com.br/jornal/2011/05/ renato-rovai-a-logica-da-revolucao-no-egitofoi-a-logica-da-blogosfera/

12. VIANA, Nildo. A internet e as rebeliões populares no mundo árabe. Disponível no site Informe e Crítica, acesso em 28 de janeiro de 2011. Disponível em HYPERLINK " "http://informecritica. blogspot.com/2011/01/internet-e-asrebelioes-populares-no.html" _ _ http:// informecritica.blogspot.com/2011/01/ internet-e-as-rebelioes-populares-no.html .
Endereço para Correspondência:

Rogério Martins de Souza

rogerms@uol.com.br

Rua Teixeira Franco 20-201,

Ramos, Rio de Janeiro - RJ

CEP: 21060-130 